\title{
Non-criteria manifestations in primary antiphospholipid syndrome: a French multicenter retrospective cohort study
}

Alexis F. Guédon ${ }^{1 \dagger}$, Jennifer Catano ${ }^{1 \dagger}$, Laure Ricard ${ }^{1}$, Charlotte Laurent ${ }^{1}$, Claire de Moreuil ${ }^{2}$, Geoffrey Urbanski ${ }^{3}$, Sophie Deriaz ${ }^{4}$, Grigorios Gerotziafas ${ }^{5}$, Ismail Elalamy ${ }^{5}$, Alexandra Audemard ${ }^{4}$, Francois Chasset ${ }^{6}$, Sonia Alamowitch ${ }^{7}$, Jérémie Sellam ${ }^{8}$, François Maillot ${ }^{4}$, Jean Jacques Boffa ${ }^{9}$, Ariel Cohen ${ }^{10}$, Noémie Abisror ${ }^{1}$, Olivier Fain ${ }^{1}$ and Arsène Mekinian ${ }^{1 *}$

\begin{abstract}
Background: From this retrospective study, we aimed to (1) describe the prevalence and characteristics of non-criteria features in primary antiphospholipid syndrome (p-APS) and (2) determine their prognostic value.

Methods: This retrospective French multicenter cohort study included all patients diagnosed with p-APS (Sydney criteria) between January 2012 and January 2019. We used Kaplan-Meier and adjusted Cox proportional hazards models to compare the incidence of relapse in p-APS with and without non-criteria manifestations.

Results: One hundred and seventy-nine patients with p-APS were included during the study time, with a median age of 52.50 years [39.0; 65.25] and mainly women $(n=112 ; 62.6 \%)$. Among them, forty-three patients (24.0\%) presented at least one non-criteria manifestation during the follow-up: autoimmune cytopenias ( $n=17 ; 39.5 \%)$, Libman Sachs endocarditis $(n=5 ; 11.6 \%)$, APS nephropathy $(n=4 ; 9.3 \%)$, livedo reticularis $(n=8 ; 18.6 \%)$, and neurological manifestations ( $n=12 ; 27.9 \%)$. In comparison to p-APS without any non-criteria manifestations $(n=136)$, p-APS with non-criteria features had more arterial thrombosis ( $n=24 ; 55.8 \%$ vs $n=48 ; 35.3 \% ; p=0.027$ ) and more frequent pre-eclampsia $(n=6 ; 14.3 \%$ vs $n=4 ; 3.1 \% ; p=0.02)$. The prevalence of triple positivity was significantly increased in patients with non-criteria features $(n=20 ; 47.6 \%$ vs $n=25 ; 19.8 \% ; p=0.001)$. Patients with $p$-APS and non-criteria manifestations $(n=43$ ) received significantly more additional therapies combined with vitamin $\mathrm{K}$ antagonists and/or antiaggregants. Catastrophic APS (CAPS) tended to be more frequent in p-APS with non-criteria features $(n=2 ; 5.1 \%$ vs none; $p=0.074)$.

The $p$-APS with non-criteria manifestations had significantly increased rates of relapse ( $n=20 ; 58.8 \%$ vs $33 ; 33.7 \% ; p$ $=0.018$ ) in bivariate analysis, but in survival analyses, the hazard ratio (HR) of relapse was not significantly different between the two groups (HR at $1.34[0.67 ; 2.68] ; p=0.40$ ).
\end{abstract}

*Correspondence: arsene.mekinian@aphp.fr

${ }^{\dagger}$ Alexis F. Guédon and Jennifer Catano contributed equally to this work.

1 AP-HP, Hôpital Saint-Antoine, Service de Médecine Interne

and Inflammation-Immunopathology-Biotherapy Department (DMU 3iD),

Sorbonne Université, F-75012 Paris, France

Full list of author information is available at the end of the article

(c) The Author(s) 2022. Open Access This article is licensed under a Creative Commons Attribution 4.0 International License, which permits use, sharing, adaptation, distribution and reproduction in any medium or format, as long as you give appropriate credit to the original author(s) and the source, provide a link to the Creative Commons licence, and indicate if changes were made. The images or other third party material in this article are included in the article's Creative Commons licence, unless indicated otherwise in a credit line to the material. If material is not included in the article's Creative Commons licence and your intended use is not permitted by statutory regulation or exceeds the permitted use, you will need to obtain permission directly from the copyright holder. To view a copy of this licence, visit http://creativecommons.org/licenses/by/4.0/. The Creative Commons Public Domain Dedication waiver (http://creativeco mmons.org/publicdomain/zero/1.0/) applies to the data made available in this article, unless otherwise stated in a credit line to the data. 
Conclusions: The presence of non-criteria features is important to consider, as they are associated with particular clinical and laboratory profiles, increased risk of relapse, and need for additional therapies. Prospective studies are necessary to better stratify the prognosis and the management of p-APS.

Keywords: Antiphospholipid antibodies, Antiphospholipid syndrome, Non-criteria antiphospholipid syndrome

\section{Background}

Antiphospholipid syndrome (APS) is a systemic autoimmune disease characterized by vascular thrombosis, pregnancy morbidity, and persistent antiphospholipid antibodies (APL). The classification Sydney criteria consider the arterial and venous thromboses, with or without adverse obstetrical features of APS [1]. Several other features, called non-criteria manifestations, can be associated with thrombotic and obstetrical APS features [2]. These non-criteria manifestations include immune thrombocytopenia and autoimmune hemolytic anemia, livedo reticularis, Libman Sachs endocarditis, APS nephropathy, and neurological manifestations such as migraine, chorea, and longitudinal myelitis. Although these non-criteria manifestations are not specific to primary APS, some studies suggest that their presence could be associated with an increased risk of thrombosis and could be thus defined as a "high risk" APS subtype [3, 4]. Large data about primary APS (p-APS) with non-criteria manifestations and their prognostic value remain understudied. Studies about the prevalence of these various "non"-criteria" APS in p-APS and their various management remain to be better described.

From this retrospective study, we aimed to (1) describe the prevalence and characteristics of non-criteria features in a multicenter cohort of patients with p-APS and (2) determine their prognostic value in comparison to p-APS without any non-criteria features regarding overall and relapse-free survivals.

\section{Methods}

\section{Study design}

All patients diagnosed with a p-APS (Sydney criteria) between January 2012 and January 2019 from departments of internal medicine, rheumatology, nephrology, neurology, dermatology, cardiology, and hematology of Saint Antoine and Tenon hospitals from Paris and university hospitals of Brest and Tours were included in this retrospective French multicenter cohort study. Patients with systemic lupus erythematosus (SLE) or other systemic autoimmune diseases were excluded. All data, including clinical, laboratory, and treatment variables, were collected by a clinician from the medical records during the first in-hospital contact and considered as baseline parameters. The presence of non-criteria manifestations was recorded as follows: immune thrombocytopenia and/or autoimmune hemolytic anemia, livedo reticularis, Libman Sachs endocarditis, APS nephropathy, and neurological disorders among multiple sclerosis-like disease, chorea, and seizure. Migraine was considered as a non-criteria manifestation if associated with another non-criteria feature and/or abnormal magnetic resonance imaging. These features were extracted from various centers' data in a homogeneous standardized file by LR and CL and checked by AM. Combined APS patients include patients with both thrombotic APS phenotype and obstetrical APS phenotype. An ethical committee was not required for this observational study according to Helsinki law and the French institutional committee.

\section{Statistical analysis}

Descriptive analyses were expressed as proportions (\%) for categorical variables and medians with ranges for continuous variables. First, we compared phenotypes from all p-APS patients with and without non-criteria manifestations, using the non-parametric Fisher test (for qualitative variables) and the non-parametric Wilcoxon test (for quantitative variables). We used Kaplan-Meier and adjusted Cox proportional hazards models to compare the incidence of relapse in p-APS with and without non-criteria manifestations. Sex, vitamin K antagonists, and triple APL positivity status were considered as potential confounders according to the literature $[5,6]$. Proportional hazards assumptions were tested based on analysis of Schoenfeld residuals and no interaction was found between variables. Data were imputed for missing data using a multiple imputation technique. A two-sided $p$ value $<0.05$ was considered as significant. $p$ values have not been adjusted for multiple testing and should not allow inference interpretation. All analyses were performed using $\mathrm{R}$ software 3.6.0 version for Mac (Foundation for Statistical Computing, Vienna, Austria).

\section{Results \\ Prevalence of non-criteria manifestations}

One hundred and seventy-nine patients with p-APS were included during the study time, with a median age of 52.50 years $[39.0 ; 65.25]$ and mainly women $(n=$ $112,62.6 \%)$. Among them, forty-three patients (24.0\%) presented at least one non-criteria manifestation during the follow-up (Table 1). These non-criteria manifestations were autoimmune cytopenias $(n=17 ; 39.5 \%)$ 
Table 1 Non-criteria manifestations among primary APS patients

\begin{tabular}{|c|c|c|c|c|c|}
\hline Total number $=43$ & $\begin{array}{l}\text { Autoimmune } \\
\text { cytopenia }\end{array}$ & APS nephropathy & $\begin{array}{l}\text { Libman-Sachs } \\
\text { endocarditis }\end{array}$ & $\begin{array}{l}\text { Neurological non- } \\
\text { criteria }\end{array}$ & Livedo reticularis \\
\hline Number & $17(39.5)$ & $4(9.3)$ & $5(11.6)$ & $12(27.9)$ & $8(18.6)$ \\
\hline Type, $n$ & $\begin{array}{l}\mathrm{ITP}=13 \\
\text { AlHA }=1 \\
\text { Evan's syndrome = } 3\end{array}$ & - & - & $\begin{array}{l}\text { Multiple sclerosis-like } \\
\text { disease }=4 \\
\text { Migraine }=6 \\
\text { Lymphocytic recurrent } \\
\text { meningitides }=1 \\
\text { Seizures }=1\end{array}$ & - \\
\hline $\begin{array}{l}\text { Associated non-criteria } \\
\text { manifestations }\end{array}$ & $\begin{array}{l}\text { APS nephropathy } \\
\text { Livedo reticularis }\end{array}$ & $\begin{array}{l}\text { ITP } \\
\text { Livedo reticularis }\end{array}$ & $\begin{array}{l}\text { Migraine } \\
\text { Livedo reticularis }\end{array}$ & $\begin{array}{l}\text { Libman-Sachs endo- } \\
\text { carditis }\end{array}$ & $\begin{array}{l}\text { ITP } \\
\text { APS nephropathy } \\
\text { Libman-Sachs } \\
\text { endocarditis }\end{array}$ \\
\hline $\begin{array}{l}\text { Thrombotic phenotype } \\
\text { (pure), } n(\%)\end{array}$ & $10(58.8)$ & $2(50.0)$ & $2(40.0)$ & $9(75.0)$ & $4(50.0)$ \\
\hline $\begin{array}{l}\text { Obstetrical phenotype } \\
\text { (pure), } n(\%)\end{array}$ & $3(17.6)$ & $0(0.0)$ & $0(0.0)$ & $3(25.0)$ & $0(0.0)$ \\
\hline Combined APS, $n$ (\%) & $4(23.5)$ & $2(50.0)$ & $3(60.0)$ & $0(0.0)$ & $4(50.0)$ \\
\hline Triple positivity, n (\%) & $10(58.8)$ & $4(100.0)$ & $3(60.0)$ & $3(25.0)$ & $4(57.1)$ \\
\hline Relapse, $n /$ total $n(\%)$ & $10 / 12(83.3)$ & $4 / 4(100.0)$ & $1 / 5(20.0)$ & $3 / 10(30.0)$ & $4 / 5(80.0)$ \\
\hline
\end{tabular}

AIHA autoimmune hemolytic anemia, APS antiphospholipid syndrome, ITP immune thrombocytopenic purpura

(immune thrombocytopenia in 13 cases, Evan's syndrome in three cases, and autoimmune hemolytic anemia in one case), Libman Sachs endocarditis $(n=5$; $11.6 \%)$, APS nephropathy $(n=4 ; 9.3 \%)$, livedo reticularis $(n=8 ; 18.6 \%)$, and neurological manifestations ( $n$ $=12 ; 27.9 \%)$. Thrombotic APS was the most frequent type of APS associated with non-criteria features $(n=$ 26; 60.5\%), and combined APS was the most frequent APS phenotype in association with Libman Sachs endocarditis $(n=3 ; 60 \%)$.

\section{Biological and clinical profiles of non-criteria p-APS}

In comparison to $\mathrm{p}$-APS without any non-criteria manifestations $(n=136)$, p-APS with non-criteria features had more arterial thrombosis $(n=24 ; 55.8 \%$ vs $n=48$; $35.3 \% ; p=0.027)$ and more frequent pre-eclampsia $(n$ $=6 ; 14.3 \%$ vs $n=4 ; 3.1 \% ; p=0.02$ ) (Table 2). Whereas the frequencies of various APL were similar between p-APS with and without non-criteria manifestations, the prevalence of triple positivity was significantly increased in patients with non-criteria features $(n=$ $20 ; 47.6 \%$ vs $n=25 ; 19.8 \% ; p=0.001$ ).

Triple-positive p-APS with non-criteria manifestations $(n=20)$ had significantly increased rates of relapses $(12(57 \%)$ vs $6(31 \%) ; p=0.03)$ in comparison to triple-positive APS without non-criteria features ( $n$ $=25$ ), whereas other characteristics (age, follow-up, type of APS, use of immunosuppressive drugs, and hydroxychloroquine) were not significantly different.

\section{Outcome and management of $\mathrm{p}$-APS with non-criteria manifestations}

Patients with p-APS and non-criteria manifestations $(n=$ 43) received significantly more additional therapies combined with vitamin $\mathrm{K}$ antagonists and/or antiaggregants (Table 2). These additional therapies were mainly hydroxychloroquine $(n=12 ; 31.6 \%$ vs $n=19 ; 14.7 \% ; p=0.035)$ and steroids $(n=12 ; 34.3 \%$ vs $n=18 ; 14.4 \% ; p=0.016)$. During the median follow-up of 5.37 years in p-APS with non-criteria manifestations and 2.95 years in those without any non-criteria features $(p=0.19)$, the death rates were not significantly different between the two groups $(n=5 ; 13.5 \%$ vs $n=5 ; 4.9 \% ; p=0.17)$. While rare, catastrophic APS (CAPS) tended to be a more frequent complication of p-APS with non-criteria features $(n=2 ; 5.1 \%$ vs none; $p=0.074)$.

\section{Factors associated with relapse}

The p-APS with non-criteria manifestations had significantly increased rates of relapse $(n=20 ; 58.8 \%$ vs 33 ; $33.7 \% ; p=0.018$ ) in bivariate analysis, but in survival analyses, the hazard ratio (HR) of relapse was not significantly different between the two groups (HR at 1.34 $[0.67 ; 2.68] ; p=0.40$ ) (Fig. 1). Bivariate analysis of factors associated with relapse showed that relapsing patients had significantly more combined APS profile $(n=17$; $32.1 \%$ vs $n=4 ; 5.1 \% ; p<0.001)$, a previous history of preeclampsia ( $n=7 ; 13.7 \%$ versus $n=2 ; 2.6 \% ; p=0.042)$, and more non-criteria features $(n=20 ; 37.7 \%$ vs $n=14$; $17.7 \% ; p=0.018$ ) (Table 3 ). In multivariate analysis, none 
Table 2 APS characteristics and outcomes in patients with and without non-criteria manifestations

\begin{tabular}{|c|c|c|c|}
\hline & $\begin{array}{l}\text { Primary APS with non-criteria } \\
\text { manifestations } \\
(n=43)\end{array}$ & $\begin{array}{l}\text { Primary APS without non-criteria } \\
\text { manifestations } \\
(n=136)\end{array}$ & $p$ value \\
\hline Male sex, $n(\%)$ & $14(32.6)$ & $53(39.0)$ & 0.564 \\
\hline Age, years, median [IQR] & $53.00[38.50,69.50]$ & $52.00[39.00,65.00]$ & 0.758 \\
\hline \multicolumn{4}{|l|}{ APS features } \\
\hline Thrombotic phenotype (pure), $n(\%)$ & $26(60.5)$ & $86(63.2)$ & 0.884 \\
\hline Obstetrical phenotype (pure), $n(\%)$ & $6(14.0)$ & $22(16.2)$ & 0.913 \\
\hline Combined APS, $n(\%)$ & $11(25.6)$ & $29(21.3)$ & 0.708 \\
\hline Number of thrombosis, $n$ (\%) & & & 0.856 \\
\hline None & $7(16.3)$ & $24(17.6)$ & \\
\hline One & $27(62.8)$ & $79(58.1)$ & \\
\hline Two or more & $9(20.9)$ & $33(24.3)$ & \\
\hline Arterial thrombosis, $n$ (\%) & $24(55.8)$ & $48(35.3)$ & 0.027 \\
\hline Venous thrombosis, $n$ (\%) & $17(39.5)$ & $73(53.7)$ & 0.149 \\
\hline Miscarriages, $n(\%)$ & $6(14.3)$ & $13(9.9)$ & 0.615 \\
\hline Intrauterine deaths, $n$ (\%) & $6(14.3)$ & $22(16.8)$ & 0.886 \\
\hline Prematurity, $n$ (\%) & $3(7.1)$ & $7(5.3)$ & 0.956 \\
\hline IUGR, $n(\%)$ & $3(7.1)$ & $7(5.4)$ & 0.965 \\
\hline Pre-eclampsia, HELLP syndrome, $n$ (\%) & $6(14.3)$ & $4(3.1)$ & 0.020 \\
\hline CAPS, $n(\%)$ & $2(5.1)$ & $0(0.0)$ & 0.074 \\
\hline \multicolumn{4}{|l|}{ Cardiovascular risk factors } \\
\hline Arterial hypertension, $n(\%)$ & $14(51.9)$ & $38(38.4)$ & 0.299 \\
\hline Dyslipidemia, $n(\%)$ & $8(29.6)$ & $23(23.2)$ & 0.666 \\
\hline Tobacco, $n(\%)=1(\%)$ & $7(35.0)$ & $13(21.3)$ & 0.351 \\
\hline Diabetes mellitus, $n(\%)$ & $4(19.0)$ & $8(12.5)$ & 0.699 \\
\hline Overweight, $n(\%)$ & $5(21.7)$ & $25(31.6)$ & 0.511 \\
\hline \multicolumn{4}{|l|}{ Laboratory data } \\
\hline Anti-cardiolipid IgG, IU, median [IQR] & $22.40[5.00,57.00]$ & $18.00[4.90,63.00]$ & 0.868 \\
\hline Anti-cardiolipid lgG positive, $n(\%)$ & $24(57.1)$ & $57(49.6)$ & 0.509 \\
\hline Anti-cardiolipid IgM, IU, median [IQR] & $11.00[2.00,53.35]$ & $10.00[2.20,38.20]$ & 0.980 \\
\hline Anti-cardiolipid IgM positive, $n$ (\%) & $17(43.6)$ & $46(39.7)$ & 0.807 \\
\hline Anti-ß2Gp1 lgG, IU, median [IQR] & $17.10[2.00,60.00]$ & $4.00[1.00,25.00]$ & 0.312 \\
\hline Anti- $\beta 2 \mathrm{G} p 1$ lgG positive, $n(\%)$ & $18(42.9)$ & 39 (33.6) & 0.379 \\
\hline Anti-ß2Gp1 IgM, IU, median [IQR] & $3.00[1.00,19.30]$ & $3.00[1.00,29.45]$ & 0.930 \\
\hline Anti- $\beta 2 \mathrm{Gp} 1$ IgM positive, $n(\%)$ & $13(32.5)$ & $36(31.0)$ & 1.000 \\
\hline $\mathrm{LAC}, n(\%)$ & $19(63.3)$ & $51(61.4)$ & 1.000 \\
\hline Triple positivity, $n(\%)$ & $20(47.6)$ & $25(19.8)$ & 0.001 \\
\hline \multicolumn{4}{|l|}{ Treatment and outcomes } \\
\hline Antinuclear antibodies, $n$ (\%) & $15(40.5)$ & $22(23.2)$ & 0.075 \\
\hline Vitamin K antagonists, $n(\%)$ & $31(77.5)$ & $81(64.8)$ & 0.193 \\
\hline Antiplatelet therapy, n (\%) & $19(50.0)$ & $58(45.3)$ & 0.746 \\
\hline Hydroxychloroquine, $n$ (\%) & $12(31.6)$ & $19(14.7)$ & 0.035 \\
\hline Steroids, $n(\%)$ & $12(34.3)$ & $18(14.4)$ & 0.016 \\
\hline Relapse, $n /$ total $n(\%)$ & 20/34 (58.8) & $33 / 98(33.7)$ & 0.018 \\
\hline Death, $n /$ total $n(\%)$ & $5 / 37(13.5)$ & $5 / 103(4.9)$ & 0.167 \\
\hline Time to relapse, years, median [IQR] & $3.58[1.23,12.54]$ & $1.71[0.48,5.77]$ & 0.260 \\
\hline Follow-up, years, median [IQR] & $5.37[0.96,11.98]$ & $2.95[1.09,7.83]$ & 0.191 \\
\hline
\end{tabular}

APS antiphospholipid syndrome, CAPS catastrophic antiphospholipid syndrome, HELLP hemolysis, elevated liver enzymes, and low platelet count, IUGR intrauterine growth restriction, $L A C$ lupus anticoagulant 
Time to relapse according to non criteria APS status

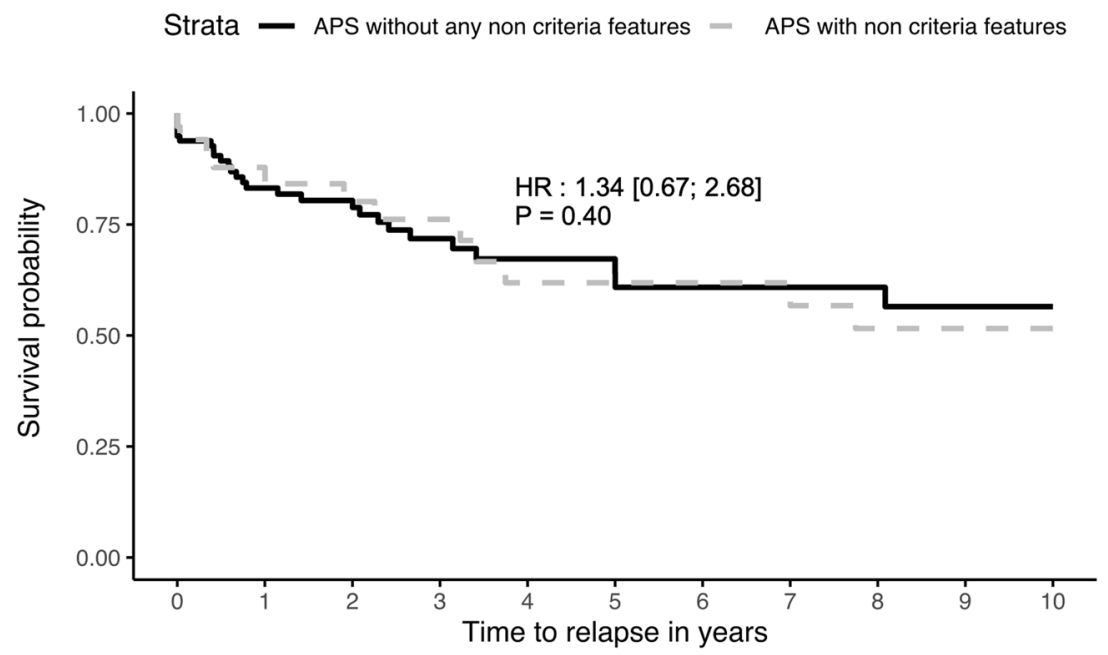

Number at risk

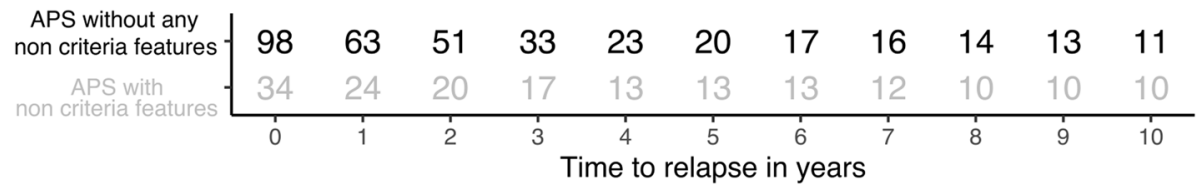

Fig. 1 Time to relapse according to non-criteria APS status

of these risk factors was independently associated with the risk of relapse (Table 4).

\section{Discussion}

From this cohort of p-APS, the main findings are that (1) p-APS with non-criteria features have an increased prevalence of severe features such as arterial thrombosis and pre-eclampsia, (2) triple positivity is increased in p-APS with non-criteria features, and (3) p-APS with non-criteria features might have a poorer prognosis, as suggested by the increased need for additional therapies.

There is still no clear consensus on the exact definitions of non-criteria APS. A recent consensus paper proposed a classification in four categories, including "clinical noncriteria APS patients," who were patients presenting noncriteria manifestations and APL positivity fulfilling the classification criteria [7]. The prevalence of non-criteria features in p-APS varies according to the studied cohorts and depends on the inclusion criteria, in particular, the exclusion of associated SLE. In an Italian study on 200 women with p-APS ongoing a pregnancy, 39 (19.5\%) had non-criteria manifestations, mainly livedo reticularis, valvulopathy, and autoimmune cytopenias [8]. Among 99 female obstetrical APS patients from the APS ACTION registry, livedo reticularis was present in 35\%, thrombocytopenia in $44 \%$, and valvulopathy in $15 \%$, but the presence of non-criteria features was not associated with the first thrombosis [9]. In the European registry of 1000 p-APS and SLE-associated APS, non-criteria features were commonly observed, including thrombocytopenia (8.7\%), livedo reticularis (8.1\%), autoimmune hemolytic anemia (4\%), valve thickening/dysfunction (4.6\%), and epilepsy (3.2\%) [10]. The prevalence of these non-criteria features in cohorts of p-APS is still not well-established, and a third of our patients have at least one non-criteria feature in this unselected p-APS cohort without any SLE.

Triple positivity was recently demonstrated as a particular laboratory feature associated with an increased risk of thrombosis and obstetrical relapses and a severe APS course. Patients with APS and triple positivity for aPL are at high risk of developing future thromboembolic events with a cumulative incidence of thrombosis at $12.2 \%$ (95\% CI, 9.6-14.8) after 1 year, $26.1 \%(95 \% C I$, 22.3-29.9) after 5 years, and $44.2 \%$ (95\% CI, 38.6-49.8) after 10 years [5]. Among APL asymptomatic carriers, none of the baseline characteristics was predictive of risk of first thrombosis, and the strongest association was found in triple aPL-positive carriers: odds ratio 3.38 (95\% CI 1.24-9.22) [11]. Patients with triple aPL positivity had a higher rate of pregnancy complications, despite the fact that they were more frequently receiving lowdose aspirin with low molecular weight heparin [12]. 
Table 3 Factors associated with relapse: comparison of patients with and without relapses

\begin{tabular}{|c|c|c|c|}
\hline & $\begin{array}{l}\text { APS patients without any relapse } \\
\text { during follow-up } \\
(n=79)\end{array}$ & $\begin{array}{l}\text { APS patient with relapse during } \\
\text { follow-up } \\
(n=53)\end{array}$ & $p$ value \\
\hline Male sex, $n(\%)$ & $23(29.1)$ & $21(39.6)$ & 0.286 \\
\hline Age, years, median [IQR] & $53.50[38.75,66.25]$ & $60.50[40.75,69.25]$ & 0.343 \\
\hline \multicolumn{4}{|l|}{ APS features } \\
\hline Thrombotic phenotype (pure), n (\%) & $61(77.2)$ & $33(62.3)$ & 0.096 \\
\hline Obstetrical phenotype (pure), n (\%) & $14(17.7)$ & $4(7.5)$ & 0.158 \\
\hline Combined APS, $n(\%)$ & $4(5.1)$ & $17(32.1)$ & $<0.001$ \\
\hline Number of thrombosis, $n$ (\%) & & & $<0.001$ \\
\hline None & $15(19.0)$ & $6(11.3)$ & \\
\hline One & $53(67.1)$ & $22(41.5)$ & \\
\hline Two or more & $11(13.9)$ & $25(47.2)$ & \\
\hline Arterial thrombosis, $n(\%)$ & $28(35.4)$ & $23(43.4)$ & 0.461 \\
\hline Venous thrombosis, $n(\%)$ & $40(50.6)$ & $32(60.4)$ & 0.356 \\
\hline Miscarriages, $n(\%)$ & $10(13.2)$ & $6(11.8)$ & 1.000 \\
\hline Intrauterine deaths, $n$ (\%) & $5(6.6)$ & $5(9.8)$ & 0.745 \\
\hline Prematurity, $n(\%)$ & $4(5.3)$ & $4(7.8)$ & 0.830 \\
\hline IUGR, $n(\%)$ & $1(1.3)$ & $3(5.9)$ & 0.362 \\
\hline Pre-eclampsia, HELLP syndrome, $n$ (\%) & $2(2.6)$ & $7(13.7)$ & 0.042 \\
\hline CAPS, $n(\%)$ & $0(0.0)$ & $2(3.8)$ & 0.304 \\
\hline \multicolumn{4}{|l|}{ Cardiovascular risk factors } \\
\hline Arterial hypertension, $n(\%)$ & $23(39.0)$ & $13(41.9)$ & 0.964 \\
\hline Dyslipidemia, $n$ (\%) & $11(18.6)$ & $8(25.8)$ & 0.603 \\
\hline Tobacco, $n(\%)=1(\%)$ & $9(17.0)$ & $7(35.0)$ & 0.179 \\
\hline Diabetes mellitus, $n$ (\%) & $9(15.8)$ & $3(15.0)$ & 1.000 \\
\hline Overweight, $n(\%)$ & $7(15.9)$ & $9(32.1)$ & 0.185 \\
\hline \multicolumn{4}{|l|}{ Non-criteria features } \\
\hline Non-criteria features, $n(\%)$ & $14(17.7)$ & $20(37.7)$ & 0.018 \\
\hline Number of non-criteria features, median [IQR] & $0.00[0.00,0.00]$ & $0.00[0.00,1.00]$ & 0.007 \\
\hline \multicolumn{4}{|l|}{ Laboratory data } \\
\hline Triple positivity, $n(\%)$ & $17(23.0)$ & $18(36.7)$ & 0.147 \\
\hline Antinuclear antibodies, $n(\%)$ & $11(19.6)$ & $11(29.7)$ & 0.384 \\
\hline \multicolumn{4}{|l|}{ Treatment and outcomes } \\
\hline Vitamin K antagonists, $n$ (\%) & $39(52.7)$ & $45(90.0)$ & $<0.001$ \\
\hline Antiplatelet therapy, n (\%) & $30(39.0)$ & $26(53.1)$ & 0.171 \\
\hline Hydroxychloroquine, n (\%) & $6(7.8)$ & $16(32.7)$ & 0.001 \\
\hline Steroids, $n(\%)$ & $10(13.0)$ & $14(29.8)$ & 0.039 \\
\hline Death, $n(\%)$ & $5(13.5)$ & $5(4.9)$ & 0.167 \\
\hline Follow-up, years, median [IQR] & $5.37[0.96,11.98]$ & $2.95[1.09,7.83]$ & 0.191 \\
\hline
\end{tabular}

APS antiphospholipid syndrome, CAPS catastrophic antiphospholipid syndrome, HELLP hemolysis, elevated liver enzymes, and low platelet count, IUGR intrauterine growth restriction

The increased prevalence of triple-positive APS was also noted near $50 \%$ of refractory APS patients from the European retrospective cohort [13]. In our study, near half of APS with non-criteria features presented a triple positivity (versus $20 \%$ in those without non-criteria features), conferring risk of severe course and risk of relapse. However, one major limitation of our study was the small size of our sample with available follow-up date, resulting in low statistical power. This might explain the reason why we do not find any difference between patients with and without non-criteria manifestation in our survival analyses, though the bivariate analysis was significantly different. The not-standardized definition of non-criteria APS features could be another important publication bias. 
Table 4 Univariate and multivariate factors associated with relapse

\begin{tabular}{llll}
\hline & HR & $\mathbf{9 5 \% ~ C l ~ ( H R ) ~}$ & p value \\
\hline Univariable Cox model (outcome:relapse) & & \\
APS non-criteria features & 1.34 & {$[0.67 ; 2.68]$} & 0.402 \\
Multivariable Cox model (outcome:relapse) & & \\
APS non-criteria features & 1.35141 & {$[0.63623 ; 2.87052]$} & 0.43334 \\
Male sex & 1.39057 & {$[0.7032 ; 2.74984]$} & 0.34323 \\
Vitamin K antagonists & 2.45312 & {$[0.89569 ; 6.71861]$} & 0.08081 \\
Triple positivity & 0.80880 & {$[0.3626 ; 1.80409]$} & 0.60416 \\
\hline
\end{tabular}

APS antiphospholipid, $\mathrm{Cl}$ confidence interval, $H R$ hazard ratio

The definition and stratification of risk profile in p-APS are of particular interest, as the management of APS is still mainly based on obstetrical or thrombotic clinical phenotype. Indeed, despite several data about the unfavorable outcome, in particular of triple-positive patients, of p-APS patients with positive antinuclear autoantibodies and lupus-like profile (unpublished personal data) or increased Global Anti-Phospholipid Syndrome Score (GAPPS) score, there is actually no real therapeutic adjustments according to these various prognostic risk factors. The value of additional therapies, in particular in obstetrical APS, has been studied, showing promising results using low-dose steroids, hydroxychloroquine, or plasma exchanges $[14,15]$. The value of additional therapies, particularly hydroxychloroquine, as illustrated in our cohort, should be better determined, in the specific subset of patients with noncriteria features $[16,17]$.

\section{Conclusion}

The presence of non-criteria features in p-APS patients is important to consider, as they are associated with particular clinical and laboratory profiles, increased risk of relapse, and need for additional therapies. Prospective studies are necessary to better stratify the prognosis and management of $\mathrm{p}$-APS.

\section{Abbreviations \\ AlHA: Autoimmune hemolytic anemia; APL: Antiphospholipid; APS: Antiphos- pholipid syndrome; CAPS: Catastrophic antiphospholipid syndrome; GAPPS: Global Anti-Phospholipid Syndrome Score; HELLP: Hemolysis, elevated liver enzymes, and low platelet count; ITP: Immune thrombocytopenic purpura; IUGR: Intrauterine growth restriction; LAC: Lupus anticoagulant; p-APS: Primary} antiphospholipid syndrome; SLE: Systemic lupus erythematosus.

\section{Acknowledgements}

None

\section{Authors' contributions}

All coauthors participated in the study design and data analysis. AG and AM completed the manuscript, and all coauthors approved the final version.
Authors' information

Done for all coauthors and all acknowledge for the data and manuscript content.

Funding

None

\section{Availability of data and materials}

Yes. Arsene Mekinian consented to the full data availability.

\section{Declarations}

\section{Ethics approval and consent to participate}

An ethical committee was not required for this observational study according to Helsinki law and the French institutional committee. Yes, obtained from patients and coauthors

\section{Consent for publication}

Yes, obtained from patients and coauthors

\section{Competing interests}

The authors declare that they have no competing interests.

\section{Author details}

${ }^{1}$ AP-HP, Hôpital Saint-Antoine, Service de Médecine Interne and InflammationImmunopathology-Biotherapy Department (DMU 3iD), Sorbonne Université, F-75012 Paris, France. ${ }^{2}$ Service de Médecine Interne, CHRU de Brest, Brest, France. ${ }^{3}$ Service de Médecine Interne et Immunologie Clinique, Centre Hospitalier Universitaire d'Angers, Angers, France. ${ }^{4}$ Service de Médecine Interne, Hôpital Tours, Tours, France. ${ }^{5}$ Sorbonne Université, AP-HP, Hôpital Tenon, Service de Hémostase et Hématologie biologique, F-75012 Paris, France. ${ }^{6}$ Sorbonne Université, AP-HP, Hôpital Tenon, Service de dermatologie et vénérologie, F-75012 Paris, France. ${ }^{7}$ AP-HP, Service des Urgences cérébro-vasculaires, Hôpital Pitié-Salpétrière, Centre de recherche de Saint Antoine, INSERM, UMRS 938, Sorbonne Université, Paris, France. ${ }^{8}$ Sorbonne Université, AP-HP, Hôpital Saint-Antoine, Service de rhumatologie, F-75012 Paris, France. ${ }^{9}$ Sorbonne Université, AP-HP, Hôpital Tenon, Service de népjrologie, F-75012 Paris, France.

${ }^{10}$ Sorbonne Université, AP-HP, Hôpital Saint-Antoine, Service de cardiologie, F-75012 Paris, France.

Received: 12 May 2021 Accepted: 14 January 2022

Published online: 25 January 2022

\section{References}

1. Miyakis S, Lockshin MD, Atsumi T, Branch DW, Brey RL, Cervera R, et al. International consensus statement on an update of the classification criteria for definite antiphospholipid syndrome (APS). J Thromb Haemost. 2006;4(2):295-306.

2. Abreu MM, Danowski A, Wahl DG, Amigo M-C, Tektonidou M, Pacheco MS, et al. The relevance of "non-criteria" clinical manifestations of antiphospholipid syndrome: 14th International Congress on Antiphospholipid Antibodies Technical Task Force Report on Antiphospholipid Syndrome Clinical Features. Autoimmun Rev. 2015;14(5):401-14.

3. Sciascia S, Amigo M-C, Roccatello D, Khamashta M. Diagnosing antiphospholipid syndrome: "extra-criteria" manifestations and technical advances. Nat Rev Rheumatol. 2017;13(9):548-60.

4. Radin M, Ugolini-Lopes MR, Sciascia S, Andrade D. Extra-criteria manifestations of antiphospholipid syndrome: risk assessment and management. Semin Arthritis Rheum. 2018:48(1):117-20.

5. Pengo V, Ruffatti A, Legnani C, Gresele P, Barcellona D, Erba N, et al. Clinical course of high-risk patients diagnosed with antiphospholipid syndrome. JThromb Haemost JTH. 2010;8(2):237-42.

6. Tektonidou MG, Laskari K, Panagiotakos DB, Moutsopoulos HM. Risk factors for thrombosis and primary thrombosis prevention in patients with systemic lupus erythematosus with or without antiphospholipid antibodies. Arthritis Care Res. 2009:61(1):29-36. 
7. Pires da Rosa G, Bettencourt P, Rodríguez-Pintó I, Cervera R, Espinosa G. "Non-criteria" antiphospholipid syndrome: a nomenclature proposal. Autoimmun Rev. 2020;19(12):102689.

8. Fredi M, Andreoli L, Aggogeri E, Bettiga E, Lazzaroni MG, Le Guern V, et al. Risk factors for adverse maternal and fetal outcomes in women with confirmed aPL positivity: results from a multicenter study of 283 pregnancies. Front Immunol. 2018;9:864.

9. de Jesús GR, Sciascia S, Andrade D, Barbhaiya M, Tektonidou M, Banzato A, et al. Factors associated with first thrombosis in patients presenting with obstetric antiphospholipid syndrome (APS) in the APS Alliance for Clinical Trials and International Networking Clinical Database and Repository: a retrospective study. BJOG Int J Obstet Gynaecol. 2019;126(5):656-61.

10. Cervera R, Serrano R, Pons-Estel GJ, Ceberio-Hualde L, Shoenfeld Y, de Ramón E, et al. Morbidity and mortality in the antiphospholipid syndrome during a 10-year period: a multicentre prospective study of 1000 patients. Ann Rheum Dis. 2015;74(6):1011-8.

11. Yelnik CM, Urbanski G, Drumez E, Sobanski V, Maillard H, Lanteri A, et al. Persistent triple antiphospholipid antibody positivity as a strong risk factor of first thrombosis, in a long-term follow-up study of patients without history of thrombosis or obstetrical morbidity. Lupus. 2017:26(2):163-9.

12. Lazzaroni M-G, Fredi M, Andreoli L, Chighizola CB, Del Ross T, Gerosa M, et al. Triple antiphospholipid (aPL) antibodies positivity is associated with pregnancy complications in aPL carriers: a multicenter study on 62 pregnancies. Front Immunol. 2019:10:1948.

13. Mekinian A, Alijotas-Reig J, Carrat F, Costedoat-Chalumeau N, Ruffatti A, Lazzaroni MG, et al. Refractory obstetrical antiphospholipid syndrome: features, treatment and outcome in a European multicenter retrospective study. Autoimmun Rev. 2017;16(7):730-4.

14. Mekinian A, Kayem G, Cohen J, Carbillon L, Abisror N, Josselin-Mahr L, et al. Obstetrical APS: is there a place for additional treatment to aspirinheparin combination? Gynecol Obstet Fertil Senol. 2017:45(1):37-42.

15. Alijotas-Reig J. Treatment of refractory obstetric antiphospholipid syndrome: the state of the art and new trends in the therapeutic management. Lupus. 2013;22(1):6-17.

16. Mekinian A, Costedoat-Chalumeau N, Masseau A, Tincani A, De Caroli S, Alijotas-Reig J, et al. Obstetrical APS: is there a place for hydroxychloroquine to improve the pregnancy outcome? Autoimmun Rev. 2015;14(1):23-9.

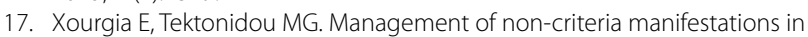
antiphospholipid syndrome. Curr Rheumatol Rep. 2020;22(9):51.

\section{Publisher's Note}

Springer Nature remains neutral with regard to jurisdictional claims in published maps and institutional affiliations.

Ready to submit your research? Choose BMC and benefit from:

- fast, convenient online submission

- thorough peer review by experienced researchers in your field

- rapid publication on acceptance

- support for research data, including large and complex data types

- gold Open Access which fosters wider collaboration and increased citations

- maximum visibility for your research: over 100M website views per year

At BMC, research is always in progress.

Learn more biomedcentral.com/submissions 